\title{
DABILEN HERRIA: MUSIKA MUGIMENDUAN
}

\author{
Jon Mantzisidor Uria \\ Universidad del País Vasco / Euskal Herriko Unibertsitatea. Dpto Dibujo
}

\section{Laburpena}

Testuak herri musikan ohikoa izan den musikarien mugimendua aztertzen du, soinuaren espazializazioa eta soinu iturri mugikorren erabileran zentratuz. Dantza eta musikarien arteko harremana ere kontutan hartzen da, ibiltzea eta soinua sortzearekin batera . Iturengo joaleak, txistulariak, trikitilariak, albokariak, txorroskileroak, txarangak, danborradak, prozesioak aipatzen dira. Ondoren, musika kultuarekiko konparaketa egiten du testuak, non musikarien kokapen eta parte hartzeak estatikotasunera jo izan duen. Haren adar berrienean ere, musika garaikidean, ez da soinu-sortzaileak mugimenduan jartzen dituen lan asko topatzen, kasu bakan batzuetan izan ezik. Charles Ives, K. Stockhausen, P. Oliveros, Llorenc Barber, Fredrik Rasten, eta beste zenbait egileren lanak ikertzen dira espazializazio eta mugimendu kontzeptuetan nolako garapenak izan diren ikusteko.

\section{Hitz gakoak: ESPAZIALIZAZIOA; MUGIMENDUA; HERRI MUSIKA; GARAIKIDEA; ESTATIKOTASUNA}

\section{ROLLING TONE: MUSIC IN MOVEMENT}

\section{Abstract}

The text analyzes the use of musicians in movement, a resource that has been common in popular music, focusing on the spatialization of sound and the use of mobile sound sources. The relationship between dance and musical performance is also taken into account, as well as the relationship between walking and the generation of sound. There are analysis of the Ituren joaleak, txistularis, trikitilaris, albokaris, sharpeners, txarangas, tambourines, processions. Next, the text makes a comparison with cultured music, in which the location and parformativity of the musicians has tended towards the static. In its most recent branch, contemporary music, there are not many works where musicians get moving and travel the space, except in some isolated cases. The works of Charles Ives, Karlheinz Stockhausen, Pauline Oliveros, Llore Barber, Fredrik Rasten, and other serve the investigation to see the developments in the concepts of spatialization and sound sources in movement.

Keywords: SPATIALIZATION; MOVEMENT; POPULAR MUSIC; CONTEMPORARY; STATICISM

Mantzisidor Uria, Jon. 2021. "Dabilen herria: Musika mugimenduan". AusArt

9 (1): 25-44. DOI: 10.1387/ausart.22663

\section{AUSART}




\section{DABILEN HERRIA: MUSIKA MUGIMENDUAN}

Testu honek musikaren espazializazioa eta batez ere musikariek mugimenduan jotzen dutenean sortzen diren erlazioak aztertzea du xede; alde batetik musikari eta entzule arteko erlazioa eta baita musikari eta inguruaren artekoa ere.

\section{HERRI MUSIKA: DEIAK, KANTUA, DANTZA, KALEJIRA}

Orokorrean harturik, herri musikan interpreteek espazioan zehar higitzeko gaitasuna izatea ohikoa izan da, hein handi batean instrumentuen izaerak eta emanaldien egiturak ahalbidetzen zuten. Herri musika diogunean, elektrizitatea eta anplifikazioa erabiltzen hasi aurretikako herri musika tradizioari buruz ari gara

Instrumentu akustikoak ziren, tamaina txikikoak eta eramangarriak, ez oso garestiak ezta oso konplikatuak ere fabrikazio aldetik, herriko jendeak eskuratzeko modukoak alegia. Kanpoan gelditzen ziren Elizako organo eta harmoniumak edo nobleziak eta ondoren burgesiak izan zitzaketen piano eta bestelako instrumentu sofistikatu eta izatez estatikoagoak.

Euskal herriko herri musikan zentratzen bagara, hizpide ditugun instrumentuak txistu, txirula, alboka, atabal, pandero, dultzaina, soinu txiki, haize instrumentu eta horrelakoak lirateke. Instrumentu hauek gehienbat kalean edo espazio irekietan jotzen ziren, baita etxe-baserrietako espazio itxietan ere, baina ez zegoen horrelako musika emanaldietarako areto espezializaturik.

Espazio irekietan erabiltzen ziren instrumentu hauetako batzuk dei edo seinale funtzioa betetzen zuten instrumentu sinple eta emaitza akustiko mugatukoak ziren, adibidez herriko bandoa irakurri aurretik jotzen ziren atabal, adar, korneta, zintzarri eta antzekoak.

Saltzaileen oihu eta kantu laburrek ere seinale zentzu hori izaten zuten, berdin herriz-herriko ibili ohi ziren konpontzaile eta bestelako ofizioetako langileen doinuek ere. Agian adibiderik argiena txorroskileroaren doinua izango litzateke; kalean urrun, pixkanaka datorren txorroskileroak bere presentzia adierazten du 
pan-txirula txiki batekin, beti antzeko nota sekuentziak eginaz . Txorroskilero bakoitzak bere doinua izan ohi du, bere marka propioa.

Baserri giroan, mugimendua eta desplazamenduak ezagutzeko balio duten bestelako soinu-markak, abereei jarri ohi zaizkien zintzarrietan aurki ditzakegu. Haien jabeak ezagutzeko moduko soinua aukeratuz eta abereak ikusmena iristen ez den lekuetara mugitu diren jakiteko balio dutenak.

Beste funtzio batekin erabili izan zen adarra, deiadar-mendi batetik bestera soinua eginaz, tonu aldaketa oso mugatuko instrumentu arkaiko honekin (zezen edo gisako baten adar hustua) bailaratik bailarako komunikazioa ahalbidetuz.

Antzeko helburuz erabili ziren irrintzi, txalaparta edo elizetako ezkilak ere, distantzia luzeetara entzunak izateko gaitasuna zutenak. Ezkilen erritmo eta tamaina ezberdinetako kanpai konbinaketen bidez, jendeak ezagutzen zituen kodeak erabiltzen ziren mezu edo seinale argiak emateko inguruko biztanleei, zela elizkizun, heriotza ala sute.

Txalaparta eta kirikoketaren kasuan ere, biak lana eta sagardoaren munduari lotuak, bazuten biek ere dei funtzio hori; ez agian txalapartari eman ohi izan zaion komunikazio ahalmen sofistikatuarekin baizik eta seinale sinpleago moduan: kirikoketa zuzenean sagarra ohol gainean zanpatzetik sortua, lanaren ondorio. Bere mezua lan huraxe bera: hemen sagardoa egiten ari gara. Lanari loturiko beste musiketan bezala eginkizunak eta gailuen izaera berak (zanpatzeko erreminta luze astunak) erritmo jakinak sortzen ditu. Txalapartaren kasuan badirudi sagardoa edateko prest zegoenean jotzen zela ingurukoei horren berri emateko; taula gainean hura ere, makil laburragoekin. Instrumentu hauen izaera dela eta, ohol luze astunak, leku batean estatiko jotzen zen, nahiz eta haren soinua inguru guztian barreiatu.

Ahotsa edo kantua ere ez da mugimenduan egin ohi den jarduera bat. Batetik bestera mugituz, baserriz baserri eta kalez kale kantatzen duten taldeak, izan gabon koro edo Santa eskekoak, desplazamenduetan ez dute abesten normalki, eta behin lekura iritsita, geldirik hasten dira kantuan. Bertsolari edo koplariarekin doazenean ere hark bere lana geldirik egiten du.

Santa eskeko makilek bai egiten dute ibilian etorriaren erritmoaren errepika bat behin geldirik daudenean ere, haren oihartzun modukoa, lurra neguko lozorrotik iratzartzeko helburu erritualez. 
Laneko kantu batzuk egon daitezke jardunean kantatzeko martxa erritmoa dutenak adibidez "Nork egin du gure galde" Iñaki Eizmendi Basarriren bertso ezagunak, 36ko gerra ondoren Aiako harrietan lan behartuetan zebilela idatziak.

Zuberoako Pastoralak herri antzerkietan ematen da ibilian eta kantuan aldi berean egiten den une bat, ohiko elementu formala errepikatua dena urtez-urteko pastoral ezberdinetan. Banaka egiten dute kantuan, batzuetan elkarrizketa moduan, eta bi tonudun kopla erdi errezitatu erdi kantatua aurkezte dute oholtzan oinez dabiltzan bitartean. Pausoen erritmo bizia makil batekin azpimarratzen da erritmoaren bigarren kolpean.

Laburki aipatu behar da dantzariak ere sarri musikari direla, egia esan beti diren arren, beti egiten baitute soinua oinekin, gorputzarekin. Ahaztu gabe begiz hautemandako erritmoa eta dinamikak ere musika erritmo eta dinamika direla. Dantzarien oinen zarata, orkatiletan jarritako txintxarriekin areagotua, eskuz egindako kriskitinak, eskuko bestelako perkusio instrumentuekin, makil kolpeak lurrean, makila makilaren kontra, zahagi puztuetan, etab, denak sortzen du dantzaren jarduerarako erritmo eta aldi berean erritmo hau mugimendu beraien ondorio dira. Hori hala izanik ere, gehienetan soinua egitearen ardura hutsa duten musikariek laguntzen dituzte dantzariak, dela txistu dela soinu. Gogoan hartu behar dira baita ere, oso orokorrean hitz eginda, dantzen konfigurazioak espazioan: esparru jakin baten mugetatik irten gabe egiten dena, plaza batean adibidez, eta bestetik, kalejiran egiten dena, espazio luzeagoak korrituz.

Azken honen adibide esanguratsua da Nafarroako Ituren eta Zubietako joaldunena, erritmoa ibiliak berak ematen diena. Binaka lerrokaturiko taldeek animalien trosta moduko erritmoa bizkarrean lotuta dituzten joareekin azpimarratzen dute eta soinuak bideetan aurrera egiten du herriak alderik alde zeharkatuz. Joare handi hauek basapiztiak eta izpiritu txarrak uxatzeko erabiltzen omen ziren.

Dantzaren eremutik musikarien eremura kalejiraren ideiari eutsiz, adibide asko ditugu musika herrikoietan. Bertakoekin jarraituz, txistulariak, trikitilariak edo dultzaineroak ditugu kale soinu eta ibiliarekin erlazionatzen ditugun taldeak. Mendi erromeria edo herrietako kalejiretan txistua, esku bakarrarekin jo ahal dena horrela bestea danbolinarekin erritmoa egiteko utziaz, oso erosoa da bidean joa izateko. Berdintsu gertatzen da iparraldeko xirula eta ttunttunarekin. Bestetik doinua eta perkusioa banatuta duten bikote ezberdin egonkorrak sortu 
dira instrumentuen arloan, hala nola soinu txikia eta panderoa, alboka eta panderoa, edo dultzaineroak (hauek gehiago taldean) eta atabala.

Pentsatzeko da guzti hauek ere nolabait jotzeko modua eta errepertorioa ere moldatuko zutela zeharkatzen zuten espazioaren izaera akustikoen arabera: non handitzen zen soinua erreberberazioz, non itotzen zen, non nahasten ziren notak, non errepikatzen oihartzunarekin, etab. Guzti honek beren jardunean eragina izango zuela pentsa dezakegu.

Horrez gain musika zein testuingurutan erabiltzen zen hartu behar da kontutan, ez baita gauza bera festa giroko kalejira edo ehorzketa bideko pausoa. Konpara ditzakegu lehen aipaturiko joaldunen erritmoak eta aste santuko prozesioko danbor eta tronpetak, denek egiten dute bidea, bakoitza bere erritmo, testuinguru sozial eta emaitza akustiko ezberdinekin.

Elizaren erritu eta militarren erakustaldiak, ez daitezke herri adierazpen gisa hartu ez bata ez bestea, ondo hierarkizaturiko antolaketa baitute oinarrian. Bandak, hasieran martxa militarrei estuki lotuak (martxaren erritmo, pauso sinkronizatu eta indar erakustaldi helburu izanik) pixkanaka herriak bere egingo ditu eta bestelako formak hartuko dituzte. Hor ditugu festetako txaranga edo fanfarreak, bandarekin alderatuz izaera amateur eta ludikoagoa dutenak edo AEBn kasuan musikari beltzen eskutik jazzera egin zen jauzia, marching banden tradizioetatik (inprobisatzen zuten txarangak), new orleans eta dixieland estiloetara. Puntu horretan, musikari ezberdinek jotzen zituzten bonbo, atabal eta txindatak bat eginaz bateria bezala ezagutzen dugun instrumentua sortu zen eta mugimenduan ari zitekeen taldea leku berberean jotzera pasatu zen.

Militarren erakustaldien tradiziotik herrira ekarritako kalejiretan sartuko genituzke danborradak ere, gehienbat perkusio instrumentuz osatuak, danbor eta egurrezko kupelekin. Eta danborraden modukoak, garaikideak haien aldean eta indar handiz sartu direnak gurean, bestelako erritmo eta errealitateak adierazten dituztenak, brasilgo herri tradiziotik ekarritako batukadak dira, auzoetako amateur taldeek osaturiko perkusio talde ibiltariak. 


\section{MUSIKA KULTUA ETA GAUR EGUNEKOA}

\subsection{Aretoaren ideia eta entzute arretatsua}

Herri musikatik musika kultura pasatzen garenean salto moduko bat nabarituko dugu haren forma orokorrari dagokionez, bat-batean estatikotasuna da nagusi; ez dago espazioan desplazatzen den musikaririk; horren ordez leku berean geldi eta sarri eserita ikusiko ditugu interpreteak.

Pentsa dezakegu garai batean hobeto entzuteko eta arreta ez galtzeko iritsi zela egitura estatiko horretara. Anplifikazio aurreko garaietan, anfiteatro natural edo artifizialen beharra ere sortu zen, non soinua espazioak berak bihurtzen zuen ozen, honek emanaldi guztia leku berean egitera behartuz.

Musika instrumentalaz gain kantua edo testua zegoenetan ulertzekoa da akustika oneko lekuen eta geldi egotearen alde egin izana esaten zen hartaz jabetu nahi bazen. Hor, entzutea gorputz guztiarekin egitetik (dantzaren eta bestelako parte hartzearen bidez) ${ }^{1}$ belarriekin eta adimenarekin egitera pasatzen zen, hau da, entzutetik aditzera.

Badago musikaz jabetzeko modu honetan errespetua eta giza arauen ezartze eta onartzearen ebidentzia ere; ordena kaosaren aurrean. Baita hierarkia erlazio bat ere non etzule-interprete harremana urrunagokoa bihurtzen den. Konpara dezagun kalean doan txarangarekin, non jendeak doinuak kanta eta dantzatu ditzakeen eta taldearekin nahas daitekeen musikarien gorputzak ukitzeraino.

Agertokiaren ideia ere sortzen da, fisikoa zein birtuala, zeinetan publikoak ez duen lekurik. Honen muturreko adibide bat, akusmatikan dugu, Pitagorasek bere ikasleekin erabiltzen zuen egiturari erreferentzia egiten diona. Pitagoras errezela baten atzetik mintzo zitzaien bere ikasleei, haiek entzun bakarrik egin zezaten, ikusizko estimuluetan galdu gabe. Entzute arretatsu hau musika akusmatikoa deitu izan den mugimenduan eman izan da, berau erabateko iluntasunean edo musikariak ikusten ez direla gertatzen da, entzuleak soinuan bakarrik murgiltzea bilatuz. Zerikusirik ez aurrerago ikusi ditugun herri musikako adibideekin, non sarri, joaleen kasuan adibidez, gorputzaren mugimendu eta janzkerak (ardi larru, koloretako zinta, tunturro txapel) soinua bera bezain garrantzitsuak diren. 
Musika kultuko kontzertuen baitan ematen den entzute arretatsu horren aurka Eric Satie konpositoreak, bere ohiko ikonoklasiari fidel, altzari musika bezala aurkeztu zituen hainbat pieza, zeinetan musika giroan zegoen zerbait zen baina ez nahitaez arretaz entzun beharrekoa. la oharkabean pasa zitekeen.

Satiek XX. Mende hasieran aurkeztu zuenaren bertsio eguneratua proposatzen zuen Pauline Oliverosek 70eko hamarkadan Sonic meditations liburuko testu-partitura honetan:

"1. Enhance or paraphrase the auditory environment so perfectly that a listener cannot distinguish between the real sounds of the environment and the performed sounds.

2. Become performers by not performing".

$(1971,26)$

Badago bietan inguru soinuarekin bat egiteko nahia, irudi-hondo erlazioarekin bukatu eta dena maila berean jartzeko gonbita. Musika kultuko adibide horiek nolanahi ere salbuespenak dira; orokorrean, entzute arretatsu eta errespetuko gorputz jarrera eskatzen zaizkio ikus-entzuleari. Eta bai musikari zein publikoa leku bakar batean mantentzen da geldi emanaldiak irauten duen denbora guztian. Soinu iturrien estatikotasun hori, esan bezala musikariek partiturak irakurri beharrak eta baita instrumentu batzuen tamainak ere behartzen du. Konpositore askok orkestraren egitura estatiko horretan mugimendua iradoki dezaketen estrategiak erabiltzen dituzte: haizearen soinua, itsasoarena, zalditeria batena etab, baina errealitatean lauhazkan datorren zalditeriaren irudia sortzen duten instrumentuak leku finko batean geldi daude.

Charles Ives konpositoreak sartu zituen bere lanetan zenbait atal, errealitatearen aipu moduan funtzionatzen dutenak. Musikarien mugimendua irudikatzen zuen esate baterako "Country band mach" (1905) izeneko piezan. Konpositorearen aita bera banda zuzendari izanik, Ivesek ezagutza handia zuen amerikar banden tradizioan, eta aipatu dugun konposizioan haize banda amateurren parodia moduko bat egiten du. Garai bateko banden desfile-desafioak irudikatzen ditu; batetik bestera doinu ezberdinak joaz mugitzen diren taldeak eta puntu batean topo egitean erritmo eta doinu nahaspilak sortzen dituztenak. Aldi berean, musikari ez profesional hauek jotzerakoan izan zezaketen baldarkeria imitatzen du partiturak (korneta jole mozkorra edo tempoa galtzen zuen saxo-jolea). Ivesek bere kopistari esan zion moduan "they don't always play right \& together \& it was as good either way" (Swafford 1996, 35). Jotzeko modu amateurraren imitazioaz gain konposizio 
bera martxa tradizional eta doinu abertzale amerikar txatalez osatua dago, aipua formatik edukira ere zabalduz

Esan dugun moduan, mugimendua irudikatua dago, martxa militarrak jotzen dira baina ez martxan; talde desberdinen gurutzaketa, distantzia etab entzulearen irudimenean ematen dira. Badirudi musika herrikoiak mugimenduak dakarren kaosa onartzen duela, aldiz musika kultuak gelditasuna eta ordena beharrezko dituela. Genionez, partiturak irakurri beharrak ere gelditasunera bultzatzen du; ez da erraza ibilian partitura konplexu bat irakurtzea. Eta puntu honetan gogoratu behar da partiturak idatzi eta irakurtzeko gai zirenak herri xehetik berezi zirela hasiera batean, hauek ikasketa batzuk eskatzen baitzituzten eta eliza edo klase dirudunetako kideek bakarrik zuten horretarako aukera. Musika herrikoiaren transmisioa berriz, pertsonatik pertsonarakoa izan da ia erabat. Doinuak belarriz ikasten ziren, buruz gorde sortu berriak, eta irakaspenak ere aurrez aurre egiten ziren, maisuaren atzamarrak begiratuz eta keinuak imitatuz. Hori erabat autodidaktak ez ziren kasuetan. Badago beraz, agintea-klase altuak-partiturak-musika kultua eta gelditasuna lotzen dituen hari bat. Eta bestetik, herri musika-mugimendua-dantza-kaosa eta ikasketa autodidakta lotzen dituen beste bat.

Aipatu behar da, era berean, instrumentu herrikoiak kontzertu formatuan jartzean edo musika kultua jotzean, inguru isil bat aukeratzen dela eta antolaketa estatikoa gailentzen dela. Albo batera uzten dira espazioan mugitzeko eta inguru fisiko eta akustikoarekin hartu emana izateko aukerak. Pentsa dezagun gaur egungo txistulari talde baten kontzertuan; agertokia erabiliko dute, erreala edo irudikatua eta honekiko aurrez aurre ikuslegoa izango da, sarri eserita. Hirugarren horma hori bere egingo dute.

\subsection{Soinuaren espazializazioa ARETOAN ETA KANPOKALDEAN}

Musika klasikoaren adar berriena, musika garaikidea, saiatu da eta saiatzen da espazioarekin zerikusia duten parametro hauek erabiltzen. Dena den, ehun urteko historian ez dugu musikariak mugimenduan jartzen dituen pieza askorik aurkituko. Goazen pixkanaka.

Stravinskiren hitzetan "musikaren fenomenoa gauzetan ordena jartzeko helburu bakarrarekin eskaini zaigu, haien artean, eta batez ere, gizakia eta denboraren arteko koordinazioan" (Stravinsky 1962, 54). Argi uzten du ez dela gizakia eta espazioaren arteko harremana kontutan hartzen; soilik denbora. 
Berriki aipatu dugun publiko-interpreteen aurrez-aurreko erlazio horri bestelako soluzioak eskaintzen dizkien lanak topatuko ditugu musika garaikideko zenbait egilerengan. Polikoraltasuna, hau da, agertokian orkestra zenbait azpitaldetan zatitzea litzateke espazialtasunaren lanketan lehen aukera. Har dezagun K. Stockhausenen Gruppen fur drei orchester (1957) lana: 109 musikari hiru multzotan banatuta kokatzen ditu, soinuak batetik bestera mugitzen direnaren ilusioa sortzen da taldeek errepikatzen dituzten akorde errotazioekin. Sentsazio hau areagotu egiten da publikoa hiru orkestren erdian kokatua dagoenez.

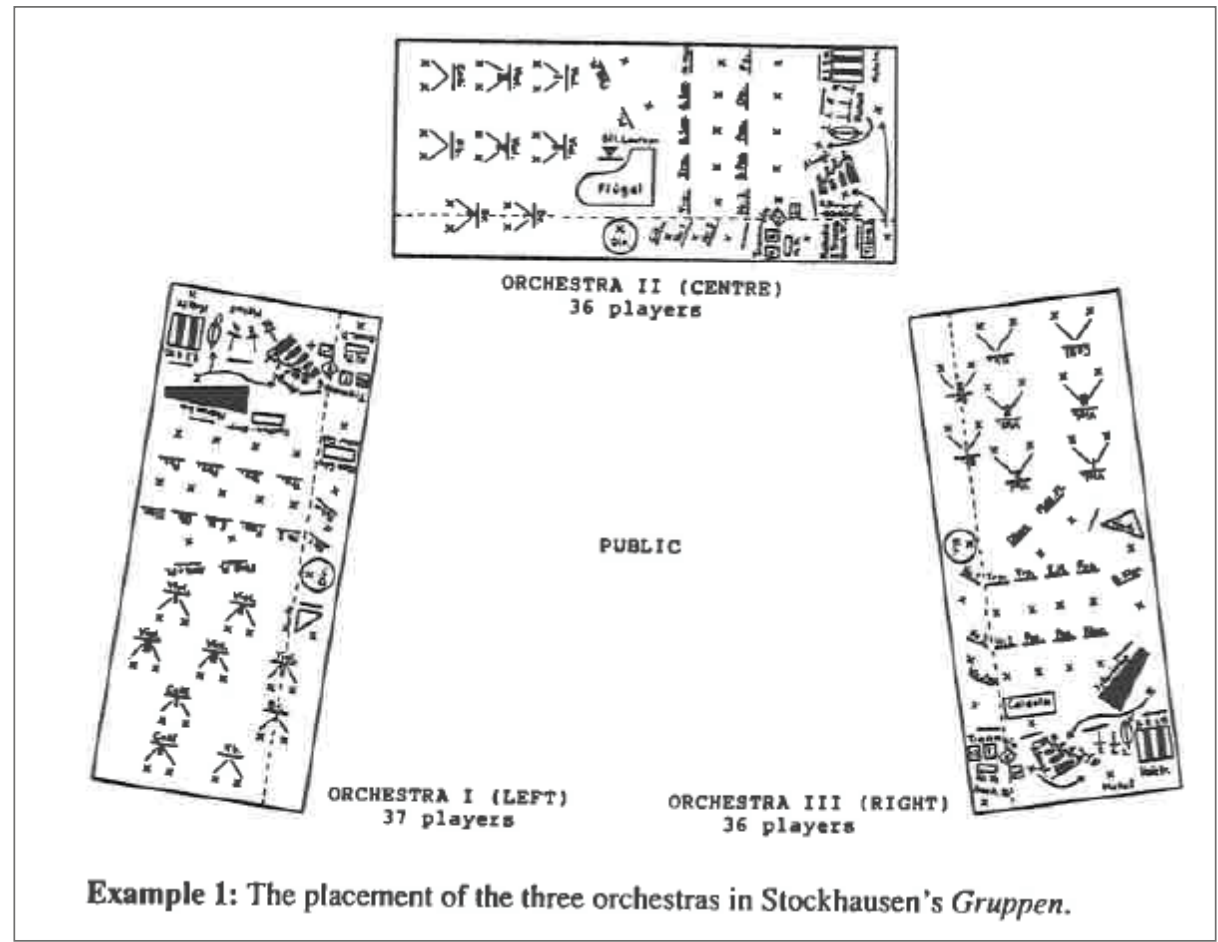

Parametro espazialen ikerketa hirugarren maila batean egon da eta esan dezakegu XX. Mendeko bigarren erdira arte ez dela konposatu espazio kontutan izanik. Hortik aurrera spazializazio lantzen duten egileak ugariak izan dira: Stockhausenez gain, P. Boulez, J. Cage, R. Murray Schafer, I. Xenakis, eta beste.

Dena den, Stockhausenen adibide horretan eta musika kultuko pieza gehienetan soinua oztoporik gabe entzuteko areto isilak hobesten dira, entzute 
arretatsurako egokiak direnak. John Cageren 1952ko "4.33" pieza izan zen inguruko zaratak ere musikaren parte izan zitezkeela argiki adierazi zuen lana. Izatez konposizioak ez baitu inguruko zarata beste soinurik. Edozein instrumentu edo instrumentu talderentzat konposaturiko hiru mugimendutako pieza honetan musikariak ez du nota bakar bat ere jotzen, baina musika kultuak bere egin dituen beste zenbait elementu bai bere horretan mantentzen ditu: publiko eta interprete estatikoak kontzertuaren momentu erritualizatu horretan bat egitea, bakoitza bere lekuan, errespetu eta isiltasuneko egoeran. Partiturak ez du zehazten pieza interpretatua izango den espazioaren ezaugarririk; areto barnean ala kanpoan joa izan daiteke.

Publikoa kontzertura konbokatua izate hori albora uzte dute kanpoaldean gertatzen diren musika adierazpide askok. 60 hamarkadatik aurrera ikusizko arteetan ere Walter de Maria, Michel Heizer, Robert Smithson eta land art mugimenduaren parte izan ziren artistek galeriaren horma zurietatik inguru fisiko natural zein urbanoetara atera zuten beren praktika. Lana inguruarekin harremanetan jartzen zen eta aldi berean publikoa ez zen bere gogoz arte lanera hurbiltzen zen hura bakarrik, bere eguneroko ibilbidean ausaz kontzertu edo arte lan batekin topo egiten zuen norbait izan zitekeen. Honen adibide dira diru truke aritzen diren kale musikari eta artistak edo orain ikusiko ditugun kanpai kontzertuak, Llorenc Barber konpositorearen lanik ezagunenak.

Barberren lanetan soinu iturriak hirietako kanpandorreetan dauden ezkilak izan ohi dira, alegia, hiri guztia hartzen du soinu espazio gisa. Nahiz eta soinu iturriak ez mugitu, kontzertura hurbildu den entzulea edo hirian dabilen ausazko entzulea mugi daiteke batetik bestera soinu masa aberats horren aldaketak esperimentatzeko. Partiturak hiri bakoitzak dituen kanpai eta topografiaren arabera konposatzen ditu espresuki. Dena den kasu honetan ere, badaude inguruko zaratetatik babestu eta musika esperientzi honetan murgiltzeko bete beharreko baldintza batzuk, kontzertu egoera ia akusmatikoa bilakatzen duena, Barber berak dionez: "Durante la noche, cuanto más tarde mejor, buscar el momento más tranquilo y silencioso en el que haya poco que ver para tener mucho que oír" (Barber 2008).

\subsection{Musikariak mugimenduan}

Kanpokaldean egiteak ahalbidetzen duen beste egoera bat musikariak edo soinu iturriak mugimenduan jartzen denekoa da. Environmental dialogue for the new Hampshire festival orchestran (1971) Pauline Oliverosek musikariak bateltxoetan kokatzen ditu laku batean, entzuleak urertzean dauden artean. 
Instrumentuekin sortzen den soinuaren abiapuntua giroan entzun daitezkeen zaraten indartzean oinarritzen da. Bateltxoak jitoan dabiltza.

2002tik soinu iturrien joan etorriari emandako Curva Chiusa erromako taldeak kontzertuak bizikleta eta motor gainean edo oinez egin ohi dituzte. Hiri eta herrietan, publikoa ez dago Oliverosen lanean bezala urertzeko puntu batean geldi, hemen batetik bestera mugi daiteke, eta Barberren lanetan gertatzen den moduan, ausazko entzuleak ere kontzertuan murgildua aurki dezake bere burua. Chris Blasen

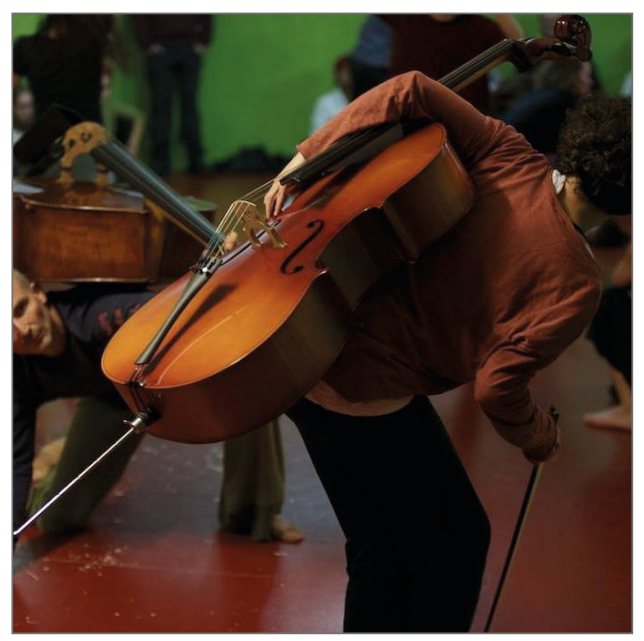
eta Alex Mendizabalek osatzen dute taldea.

Lehenago aipatu dugun moduan, instrumentuen mugikortasun posiblean zerikusi handia du instrumentuen tamaina eta izaerak, badaude astun eta traketsagoak direnak. Esate baterako gitarra klasikoa eserita jotzen da. Gitarra seikote bat mugimenduan jartzeak baditu bere zailtasunak eta mugitzeak joko duten horri eragingo dio. Horrekin lan egiten du 2019ko "Six moving guitars" lanean Fredrik Rastenenek. hiru musikari eta hiru dantzarik espazioan mugiarazten dituzte afinazio justuan dauden sei gitarra. Mugimendu berak sortzen du soinua. Dantzari-musikari banaketa lausotzen da. Diskoaren barne oharretan azaltzen denez: "The piece can also be seen as a study in how people, without necessarily being trained musicians, can act together in a musical situation based on awareness of listening and spatial orientation" (Rasten 2019).

Entzute arretatsua eta anplifikazio sistemen erabilera dela eta hain estatikoa izan den inprobisazio askean ere (onkyo edo Berlingo reductionismean pentsatu besterik ez) dantza eta musikariek bat egiten duten puntu hau landu izan da zenbait egileren eskutik. Ez gara ari dantzari eta musikarien arteko kolaborazioez, baizik eta musikaria dantzari bihurtzen denekoa, eta alderantziz, Six Moving guitars lanean ikusi dugun moduan. Inprobisazioaren arloan, Musicians in space izeneko jardueretan landu izan dute Paloma Carrasco eta David Leahy bezalako egileek, biak ere fisikoki mugikortasuna errazten ez 
duten instrumentuak eskuetan (biolontxeloa eta kontrabaxua hurrenez hurren). Inprobisazio askea eta contact dantza moldeak bat egiten duten lekuan.

\subsection{Anplifikazioa}

Partiturek eta mugitzeko nekezak diren instrumentuek adina eragin izan du beste elementu batek publiko/interpreteen estatikotasun egituran: anplifikazioak.

Elektrizitate eta bozgorailuen laguntzaz musikariak anplifikatzen hasi zirenetik are eta estatikoagoa bihurtu da haien jarduna. Soinua jasotzen duen mikrofonotik zertxobait mugituz gero publikoak dena ozen entzutetik ezer ez entzutera alda daiteke egoera. Honek dinamika jokoetarako ematen duen arren mugimenduen zurruntasuna ere ekarri du nahitaezean.

Agertokiaren beste aldean ere, publikoarenean, egoera antzekoa da: bozgorailu finkoek soinua puntu konkretu batzuetatik bakarrik igortzen dute, gehienetan bi, oholtzaren alde banatan daudenak publikoarekiko aurrez-aurre.

Dena den, bozgorailuen erabilera oinarrizko horretaz gain bestelako antolaketak ere egon daitezke. Musika elektroakustikoan honako banaketa ezar dezakegu espazioaren erabilerari dagokionez: 1) Mono. Soinu iturri bakarra 2) Estereofonia. Bi bozgorailu entzulearen aurrean, soinuaren irudipen bidimentsionala sortuz. 3) Kuadrofonia. Lau bozgorailu aretoaren izkina bakoitzean kokatuak. 4) Multifonia. Puntu ezberdinetan kokaturiko bozgorailuak, lau baino gehiago. 5) Mugimenduan dauden bozgorailuak.

Annette Vande Gorne konposatzailearentzat espazializazioa bera konposaketa elementu bilakatu zen elkarrizketa honetan azaltzen duen moduan:

The discovery of space as a possible structuring process comes naturally in composition, as well as the thing to which space is attached, the instrument to make the space. What does one need to make the space? One needs loudspeakers in a given space, and not just two loudspeakers. I discovered acousmatic music in 1971 and in 1972. Before I went to the Conservatoire National Superieur de Paris and began to compose, I gave my first concert in a church thanks to a small sound system consisting of eight loudspeakers and a spatialization console that a friend constructed for me. That 
moment was important for me because the instrument, that Bayle would name the Acousmonium in 1974, seemed essential to me.

(Anderson- en aipatua 2012, 15)

Dena den, soinu iturri finkoe anitzen erabilerak zabaldu zituen aukerez gain, goiko zerrendan 5. puntua da kontutan hartzekoa, Mugimenduan dauden bozgorailuak alegia. Aukera hau gaur egun ere teknikoki problematikoa da generadoreak edo bateriadun bozgorailuak erabiltzera behartzen baitu. Mugimenduan dauden bozgorailuak aurki ditzakegu adibidez reggae musikako Sound Sistemetan, non kamioietan jartzen zen musika ekipoa; berdin inauteri eta festetako karrozetan edo kaleko musikari elektriko eta elektrotxarangetan ere. 80 hamarkadako gazte taldeek kalean hip-hop lerro inprobisatuen oinarri erritmikoak jartzeko erabiltzen zituzten irrati kasetak gaur egun mugikorretara konektaturiko bozgorailu eramangarriengatik ordezkatu dituzte. Honekin loturik gogoratu behar dugu irrati transistore txikien ondoren sortu ziren walkman eta geroagoko musika entzungailu digitalak, telefono mugikorrera iritsi arte, non normalean entzuketa modu berri bat ezarri zuten gailuok: edonon ibilian edo geldirik, belarri barnean gertatzen den entzute esperientzia indibiduala aurikularren laguntzaz.

Airean barreiaturiko soinuetara itzuliz, badu Christian Marclayk gitarra elektriko bat kamioi bati sokaz loturik errepidean arrastaka daraman bideo ezaguna, Guitar drag (1999). Ez da zuzeneko performancea baizik eta bideoan jasotzeko egina. Urte bete lehenago Texasen ideologia zuri suprematistadun hiru gizonek James Byrd afro-amerikarra kamio atzean arrastaka eramanaz erail izana gogorarazten du. Marclayren bideoan kamioi gainean doan anplifikagailuak gitarraren kolpe eta arrasten feedback eta zaratak zabaltzen ditu txilioak bailiran.

Mugimendua eta anplifikazioa lotzen ditu K. Stockhausenen piezarik ezagunenetako batek ere, Helikopter-streich quartet (1993), non hari laukote batetako kideak lau helikopterotan doazen. Helikoptero bakoitzak hiru mikrofono ditu eta hari instrumentuen tremoloak helizeen zaratarekin bat egiten dute. Mikroek jasotako soinu hauek bozgorailu eta telebista pantailaz hornituriko auditorio batzuetan igortzen dira. Han dago publikoa. Ikusten dugunez, musikariak zeruan mugitzen diren arren, publikoak jasotzen duen emaitza bozgorailu estatiko batzuetatik dator, eta publikoa bera ere estatiko. 


\subsection{SOUNDWALK ETA ibiLALdiak}

Herri musikan ikusi ditugun interprete ibiltarien bertsio gaurkotuarekin bukatuko dugu mugimendua eta musika lotzen dituen testu hau.

Dadaren paseoen ondoren Situazionistek noraezak ekintza artistiko moduan proposatzen zituzten 60ko hamarkadan. Bide beretik jarraitu zuen Fluxus taldeak ekintza askotan, beraien testu partiturak segituz edo happening kolektiboetan. Adibidetzat har dezagun La Monte Youngen Composition 1960 No. 10, partitura ezaguna. Honela dio: "Draw a straight line and follow it". Proposamen zabalak interpretazio are zabalagoak izan ditu, asko ibiliarekin eta lekualdatzearekin zerikusia dutenak.

Lehen ere aipatu dugun Pauline Oliverosek Native (1971) partitura labur honekin bide berean jartzen gaitu: Take a walk at night. Walk so silently that the bottoms of your feet become ears (Oliveros 1971, 9). Entzutea ukitze ekintza bihurtzen da oin zolekin, ibiltzea berriz musika sortzearen.

Fluxus taldearen ekintza askotan edo Oliverosen honako honetan, interprete eta publikoaren arteko bereizketa lausotu egiten da, denak dira aldi berean egile eta interprete. Inguruan gertatzen dena ere obraren parte izatera pasatzen da. Ibiltzeak iragankorra den hortaz jabetzea eskatzen du, erabakiak hartzea norabide eta gertatzen ari denarekiko, ezustekoari irekita egotea.

Janet Cardiff en Wanås Walk (1998) piezan, entzulegoa ibilaldi bat egitera gonbidatzen da. Publikoa aurikularrekin, konpositoreak lehenagotik prestatu du ibilbide horretan entzungo den pieza. Naturako soinuak entzungo dira, sarri aurrean duten natur gune berberean grabaturikoak, baina ez beti, edo ez bakarrik. Bestelako soinuak ere izango dira eta ikusten dena eta entzuten denaren arteko dislokatze moduko bat gertatzen da. Errealitatea eta abstrakzioaren arteko krakatekoa: errealitatetzat soinu iturria ezagutzen duguneko egoera harturik eta abstrakziotzat soinuek testuinguru fisikoarekiko harreman zuzena ez dutenekoa.

Badira ikusten edo entzuten ez ditugun fenomenoak eta gure hirietan etengabean gertatzen ari direnak: argi sistema, radarrak, segurtasun aparailuak, wifiak, telefono mugikorrak... guztiek inguru elektromagnetikoak sortzen dituzte. Hauetaz inguratuak bizi gara oharkabean. 2003 tik aurrera, Christina Kubischen electric walks-ek entzungarri egiten dituzte hauek guztiak; aurikular bereziak 


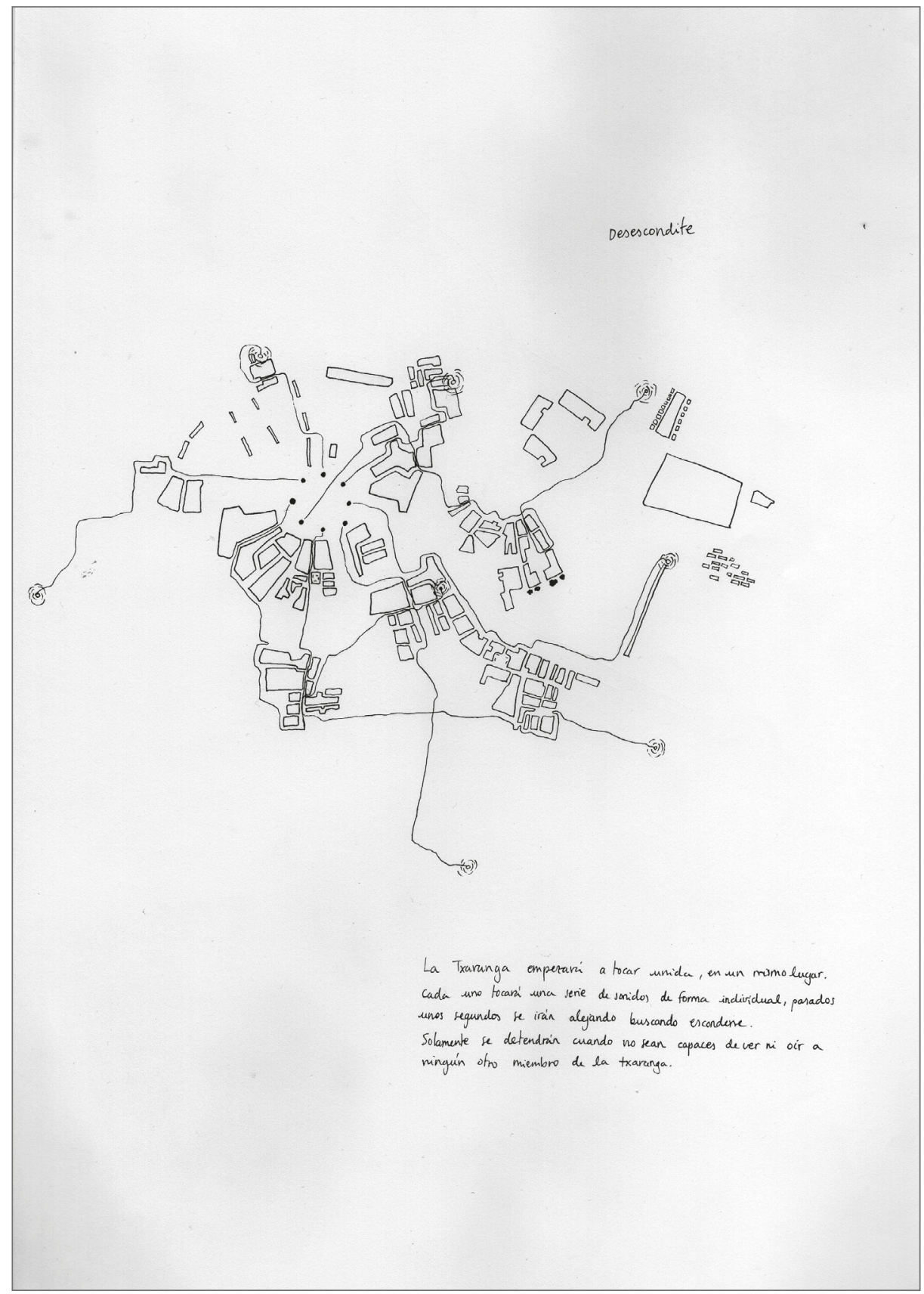


jarrita parte-hartzaileei hirian zeharreko ibilbideak proposatzen zaizkie inguru elektromagnetiko guzti hauek sortzen duten soinuaz jabetzeko.

The tuning of the world testuan R. Murray Schaferrek 'listening walk' eta 'soundwalk' bereizizituen, bigarrenean parte-hartzaileakekintza performatiboak egiteko aukera duten bitartean lehenengoan entzule pasiboagoak izango dira. Soundwalk hauei 'sound performance' izena ere eman izan zaie. Kasu hauetan artistak bestelako materiala erabil dezake: inguruko objektuen manipulaketa, poema irakurketak, grabazioen entzutea, instrumentuak jotzea, etab.

Honen adibidetzat aurkezten dugu Dallas Simpsonen The adoration of willow (1995). Ibilaldi batek Nothinghameko Trent ibaiertzeko zuhaitz batzuetaraino eramaten du ikuslegoa, eta bertan artistak bidean topaturiko objektuekin inprobisatzen du sahatsaren enbor adarretan eta inguruan.

Bukatzeko Cornelius Cardewren Scratch Orchestraren izpiritua eta Nerbioi ibaiaren ezkerraldeko Kartoi banden amateurtasuna bateratzen dituen Bilboko Txaranga Urretabizkaiaren pieza bat ekarriko dugu paperera ${ }^{2}$. Jarraibide sinpleetan oinarrituriko partituretatik abiatuz, 2017an sorturiko txaranga honen jarduna espazio eta egoerei egokituz gauzatzen da. Irudian datorren Ezezkutaleku (2019) piezak musikarien ibilia eta espazioan soinuak entzun/ ez entzutea lantzen du. Kide guztiak elkarrekin dauden puntu batetik, alde guztietarako eztanda moduan irteten dira, bakoitza bere aldetik nahi duena joaz, hiri edo herrian zehar. Beste norbaiten soinua entzuten duen bitartean norberak ere jotzen jarraitzen du, behin soinurik entzuten ez dela norbera ere isildu egiten da.

\section{ONDORIOAK}

Beste ezer baino lehen eta testuan kontzeptu hauek agertu direnez, herri musika eta musika kultuari buruz azalpen batzuk eman beharrean aurkitzen gara. Batetik, Labayru hiztegian eta Eusko Jaurlaritzaren sareko itzultzaileetan 'herri musika' 'música popular' gisa itzulia agertzen zaigu. Testuan egiten den banaketarako nahikoa litzateke horrela, herri musika musika kultutik bereizteko balio baitigu, baina zehazki zeri egiten dio erreferentzi hauetako bakoitzak? 
Etnomusikologian hiru ataletako bereizketa hau egiten da normalean:

1. Musika kultua (klasikoa, akademikoa edo artistikoa ere deitua)

2. Musika folklorikoa (folk, herri musika edo tradizionala ere deitua)

3. Musika popularra (herri musika modernoa, garaikidea edo hiritarra).

XVIII. mende-arte Europan bi musika korronte nagusi zeuden: musika kultua, idatzizko tradizioduna eta aristokraziari lotua eta musika folklorikoa (garaian musika popularra deitua), ahozko tradizioa eta gehienbat landa biztanlegoari lotua.Banaketa honek gizarte banaketa adierazten zuen. Pierre Bordieuren ideiei jarraituz, eskaintza artistiko bakoitza klase sozial bati zuzendua zegoen, haren ustez horrela efektu hirukoitza sortzen zen: klasea definitzea, banatzea eta klase batekoa izatea adieraztea. Horixe izan zitekeen bere funtzio sozial garrantzitsuena.

Kultua eta herri musika banaketa hori industri iraultzarekin hasi zen aldatzen. Hirien hazkundea eta burgesiaren indartzeak bestelako ikuskizunak sortzea ekarri zuen hirietan eta musika popularra sortu zen. Musika popular hau ez zen nazio edo herrialde konkretuekin lotuko, nazioarteko izaera izango luke eta bere generorik adierazgarrienak pop, rock, jazz, blues, musika elektronikoa, eta abar lirateke.

Aurrekoak kontutan izanik arazo bat sortzen zaigu: herri musika folklorikoa eta herri musika hiritarra (musika popularra) bi multzotan banatuak agertzen direla teoria liburu askotan. Hemen landu ditugun ideien garapenerako ordea banaketa hori ez dugu beharrezkoa ikusten.

Batetik, musika tradizionala musika popularra izan baitzen tradizio bihurtu aurretik. Pentsa dezagun, urrutira joan gabe, euskal herriko trikitiaren kasuan. Kasu paradigmatikoa. XIX. Mende bukaeran trenbideetako langile italiarrek ekarri omen zuten instrumentu berria Euskal Herrira. Trena modernitatearen sinbolo bazen bertako landa eremuko gizartearekin topo egin zuen trikitiak, hiri-herrietan bestelako musika taldeekin konpetentzia zegoenez trikitiaren tamaina eramangarriak mendiko erromerietara bideratu zuen. Han alboka eta txistua bezalako instrumentu tradizionalen dantzako errepertorioa bereganatzeaz gain garaiko modako doinuak ekarri zituen, baltsak eta dantza lotua. Argi ikusten da XIX bukaeran trikitiari musika tradizionala deitzea ez zela oso zuzena, garaiko musika berria jotzen baitzen instrumentu berri batean. 
Bestetik musika popular hiritarrak herri musika izaten jarraitzen baitu eta mantentzen ditu landa eremuko musika folklorikoari atxikitako ezaugarri asko: amateurtasuna, ahozko transmisioa, euskarri teorikoen falta, interpretatzeko espazio espezifikorik eza, etab. Pentsa dezagun hiriko bazterretan bildutako lagun taldeetan, bafle eramangarrietan erritmoak jarri eta rap kantuak inprobisatzen.

Goian aipatu ditugun hiru musika mota hauei zenbait ezaugarri atxikitzen zaizkie:

Interpreteak: folklorikoa (amateurrak), musika kultua eta popularra (profesionalak)

Hedapen bide nagusia: folklorikoa (ahozko transmisioa), kultua (musika notazioa), popularra (grabazioa)

Gizarte mota: folklorikoa (landa eremua), artistikoa (landa, industriala), popularra (industriala)

Finantzaketa XX. Mendean: folklorikoa (independentea), kultua (publikoa), popularra (enpresa librea).

Teoria eta estetika: folklorikoa eta popularra (ez ohikoa), kultua (ohikoa)

Egilea: folklorikoa (anonimoa), kultua, popularra (ez-anonimoa)

Gure testuan herri musika deitu zaion horretan musikariak ahozko transmisioan oinarritzen dira instrumentu eta errepertorioaren ikasketarako. Hau garrantzitsua dela uste dugu musika kultua berriz idatzizko tradizioan oinarritzen baita. Musikariak partitura bat izan ohi du pieza ikasterakoan eta baita jendaurrean dagoenean ere. Irakurri behar izate horrek zalantzarik gabe musikarien gorpuzkeran eragiten du estatikotasunera eramanaz. Piezak buruz ikasirik ere egilearekiko errespetuz, musikari klasikoek partitura aurrean izatera behartuak egon ohi dira. Honek egiletzaren kontzeptua eta partitura horren interpretazioaren fideltasunera garamatza, herri musikako pieza anonimo eta malguen alboan, bariazio mugagabeak onartzen dituztenak. Noski, ezer irakurri beharrik gabe, belarriz ikasitakoa edo bat-batean asmaturikoa jotzeak musikari hauek espazioan mugitzeko askoz erraztasun handiagoz uzten ditu.

Bukatzeko, badago herri musika bestelako ekintza eta erritoekin lotzen duen erlazio bat aipatu beharrekoa, sarri espazioei estuki lotuak dagoena: musika kultuaren bilakaerak musika eserita entzuten den ekintza estatiko bat izatera eraman badu inguruko zaratetatik isolaturiko kontzertu aretoetan, herri 
musikan aldiz musika leku eta ekintza bati loturik topatuko dugu gehienetan: joaleak inauterien erritoekin lotuta, trikitia dantzarekin eta mendi erromeriekin, danborradak data historikoekin, prozesioak erlijio ekintzekin, txarangak festa giroarekin, eta abar.

Herri musiketan ikusle-interprete erlazioak ere lausoagoak izan ohi dira, musika kultuan hierarkiak (konpositore, zuzendari, musikari nagusi, musikari laguntzaile, ikusle dirudun, ikusle txiro, etab) espazioan nabarmenago bereizita agertzen diren bitartean; zer esanik ez ikusle isila eta geldia izatearen betebeharraz. Nolabaiteko kode zorrotzak kristalizatu egin dira eremu horretan, musikarien estatikotasunean ere finkatu diren bezala. Hori dela eta musika kultuaren adar berrienean, musika garaikidean egindako saiakera bakanak bitxikeria moduan geratzen dira eta ez dute herri musikan topatutako adierazpideen aberastasunik, hein handi batean aretoa eta ikus-entzulearekiko harremana finko mantentzen delako.

\section{Erreferentzia bibliografikoak}

Anderson, Elizabeth. 2012. "An interview with Annette Vande Gorne”. Computer Music Journal 36(2): 10-22. https://doi.org/10.1162/COMJ_a_00116

Barber Colomer, Llorenc. 2008. Cómo se hace un concierto de campanas. Campaners de la Catedral de València (weborria), ekainak 12. http://campaners.com/php/textos php?text=2993

Beltran Argiñena, Juan Mari. 2009. Txalaparta. Donostia-San Sebastian: Nerea

Cardew, Cornelius. (1931) 2006. A reader: A collection of Cornelius Cardew's published writings. Ed., Edwin Prevost. Harlow, Essex: Copula

Debord, Guy. 1981. "Perspectives for conscious alterations in everyday life". In Situationist International anthology, edited and translated by Ken Knabb. Berkeley CA: Bureau of Public Secrects

Fischer-Lichte, Erika. (2004) 2011. Estética de lo performativo. Traducción, Diana González Martín \& David Martínez Perucha; introducción, Oscar Cornago. Madrid: Abada

Friedman, Ken, Owen Smith \& Lauren Sawchyn, eds. 2002. The Fluxus performance workbook. Digital supplement to Performance Research 7(3). London: Routledge Taylor \& Francis

Harley, Maria. 1993. "From point to sphere: Spatial organization of sound in contemporary Music (after 1950)". Canadian University Music Review 13: 123-44

Marclay, Christian. 1995. Amplification. Biennale di Venezia 1995. Venezia: Lars Müller

Murray-Schafer, Robert. 1977. The tuning of the world. New York: Knopf

— . 2006. "I have never seen a sound". Environmental \& Architectural Phenomenology Newsletter. 17(2): 10-15. http://newsletter-phenomenology.ophen.org/pub-115438 
Nyman, Michael. (1974) 2006. Música experimental: De John Cage en adelante. Traducción de Isabel Olid Báez \& Oriol Ponsatí-Murlà. Girona: Documenta Universitaria

Oliveros, Pauline. 1971. Sonic meditations. Sharon, VT: Smith Publications

Parsons, Michael. 2001. "The scratch orchestra and visual arts". Leonardo Music Journal 11: 5-11

Rasten, Fredrik. 2019. Six moving guitars. Oslo: Sofa Music. CD-ROM

Stravinsky, Igor. 1962. An autobiography. New York: Norton

Swafford, Jan. 1996. Charles Ives: A life with music. New York: Norton

Tannenbaum, Mya. 1988. Stockhausen: Entrevista sobre el genio musical. Traducido por Carlos Alonso. Madrid: Turner

Vande Gorne, Annette. 2010. "Especial JIEM 2010: Annette Vande Gorne-19/06/10". La interpretación espacial de la música acusmática-kurtsoaren lanen zatiak (Madrilgo Reina Sofía Museoa, ekainak 26-27, JIEM Jornadas de Informática y Electrónica Musical- barruan). Ars Sonora web orria. https://www.rtve.es/alacarta/audios/ars-sonora/ars-sonora-especial-jiem-2010-annette-vande-gorne-19-06-10/804989/

\section{Oharrak}

${ }^{1}$ Gaur egun egonkorrak eta betikoak diruditen ohiturak bestelakoak izan dira lehenagoko garaietan. Publiko isilaren kontzeptua esate baterako garatuz joan den zerbait izan da orain ezagutzen dugunera iritsi arte. Operetan adibidez, ikus entzuleek ere parte hartzen zuten aktoreei erantzunaz edo oihu eginaz. Tramaren parte izatera irits zitezkeen.

${ }^{2}$ Txaranga Urretabizkaia. Partiturak/s. Bilbo: Popurrit/Belleza Infinita, 2021

\footnotetext{
(Artículo recibido: 27-03-21; aceptado: 14-06-21)
} 